\title{
Low Temperature Thermal Evaporation Process for the Synthesis of $\mathrm{ZnO}$ Nanowires
}

\author{
Geun-Hyoung Lee* \\ Department of Materials \& Components Engineering, Dong-eui University, \\ 995 Eomgwangno, Busanjin-gu, Busan 614-714, Republic of Korea
}

\begin{abstract}
$\mathrm{ZnO}$ nanowires were synthesized by thermal evaporation of $\mathrm{ZnBr}_{2}$ powder at relatively low temperatures of $600-700^{\circ} \mathrm{C}$ under air atmosphere. Any catalysts and substrates were not used in the synthesis of $\mathrm{ZnO}$ nanowires. The $\mathrm{ZnO}$ nanowires had a typical diameter of $100 \mathrm{~nm}$ and lengths up to several tens micrometers. The X-ray diffraction (XRD) pattern indicated that the ZnO had hexagonal wurtzite structure. The scanning electron microscope (SEM) image showed clearly that catalyst particles existed at the tips of nanowires. The energy dispersive X-ray (EDX) analysis revealed that the catalyst particles were composed of $\mathrm{Zn}$ and O. Based on the SEM and EDX results, it was suggested that the nanowires were grown via self-catalytic growth mechanism. A strong green emission was observed in the room temperature cathodoluminescence spectrum. [doi:10.2320/matertrans.M2013156]
\end{abstract}

(Received April 24, 2013; Accepted June 24, 2013; Published August 2, 2013)

Keywords: zinc oxide, nanowire, thermal evaporation, zinc salt, low temperature

\section{Introduction}

Zinc oxide $(\mathrm{ZnO})$ is a potential material for the applications in electronics, optoelectronics and sensing such as transparent thin film transistors, ultraviolet emitting devices, solar cells and gas sensors. $\mathrm{ZnO}$ has a wide direct band gap of $3.37 \mathrm{eV}$, which makes it emit ultraviolet light. It also has a large exciton binding energy of $60 \mathrm{meV}$, resulting in an excitonic laser emission under low lasing threshold even at room temperature. So many studies have been made on $\mathrm{ZnO}$. Recently, synthesis of $\mathrm{ZnO}$ nanowires has attracted a great attention since room temperature UV laser emission was detected from $\mathrm{ZnO}$ nanowires. ${ }^{1)}$

In the recent years, various methods, including thermal evaporation, ${ }^{2)}$ pulsed laser deposition, ${ }^{3)}$ sputtering, ${ }^{4)}$ metal organic chemical vapor deposition ${ }^{5)}$ and sol-gel process, ${ }^{6}{ }^{6}$ have been developed to grow $\mathrm{ZnO}$ nanowires. Among these methods, thermal evaporation process has been commonly used due to the simplicity and low cost. The thermal evaporation process requires the growth temperature of $900^{\circ} \mathrm{C}$ or higher for growing $\mathrm{ZnO}$ nanostructures. However, it becomes increasingly more important to grow nanostructures at low temperatures for device applications. Thus a low temperature process is required for $\mathrm{ZnO}$ nanostructures growth. In addition, the conventional thermal evaporation process is carried out in vacuum and so it is a complicated process using complex vacuum system. If the synthetic process can avoid the use of vacuum system, it allows the growth of nanostructures under simpler growth conditions.

On the other hand, zinc salts such as $\mathrm{ZnBr}_{2}$ have relatively low melting $\left(394^{\circ} \mathrm{C}\right)$ and boiling points $\left(697^{\circ} \mathrm{C}\right)$. Thus it can be supposed that if zinc salts are used as zinc source in thermal evaporation synthetic method, they will be evaporated and reacted with oxygen to form zinc oxide at low temperature.

In this paper, we report the synthesis of $\mathrm{ZnO}$ nanowires by low-temperature thermal evaporation of $\mathrm{ZnBr}_{2}$ powder under

*Corresponding author, E-mail: ghl@deu.ac.kr air atmosphere and their growth mechanism. In the conventional thermal evaporation process, substrates have been used to supply the nucleation sites for the growth of $\mathrm{ZnO}$ nanostructures. So far growth mechanism and properties of $\mathrm{ZnO}$ nanostructures grown on substrates have been investigated. However, in the present experiment, any substrate was not used and $\mathrm{ZnO}$ nanostructures were synthesized in the crucible containing the source powder. It is worthwhile to investigate the morphology and growth mechanism of the $\mathrm{ZnO}$ nanostructures synthesized in the crucible.

\section{Experimental Procedure}

$\mathrm{ZnBr}_{2}$ powder with a purity of $99.999 \%$ was used as the source material for synthesizing $\mathrm{ZnO}$ nanowires. The powder was put in a alumina crucible and the crucible was covered with the lid. Then the crucible was inserted into the center of quartz tube in a horizontal tube furnace under air atmosphere. The furnace was heated to the temperatures in range of $600-900^{\circ} \mathrm{C}$ with a heating rate of $10^{\circ} \mathrm{C} / \mathrm{min}$. The powder was evaporated and reacted with oxygen in air at the temperature. After one hour of oxidation process, the furnace was turned off and cooled down to room temperature.

The oxidized products in the center of the crucibles were collected for the characterization. The morphology of the products was studied using scanning electron microscope (SEM). The components of the products were analyzed using energy dispersive X-ray (EDX) spectroscope. The crystal structure was characterized by X-ray diffractometry (XRD) with $\mathrm{Cu}-\mathrm{K} \alpha$ radiation. The cathodoluminescence (CL) measurement was taken at room temperature using CL spectroscope.

\section{Results and Discussion}

Figure 1 shows the SEM images of the as-prepared products synthesized at different temperatures of 600,700 , 800 and $900^{\circ} \mathrm{C}$ in the crucible. Nanowires are observed with 


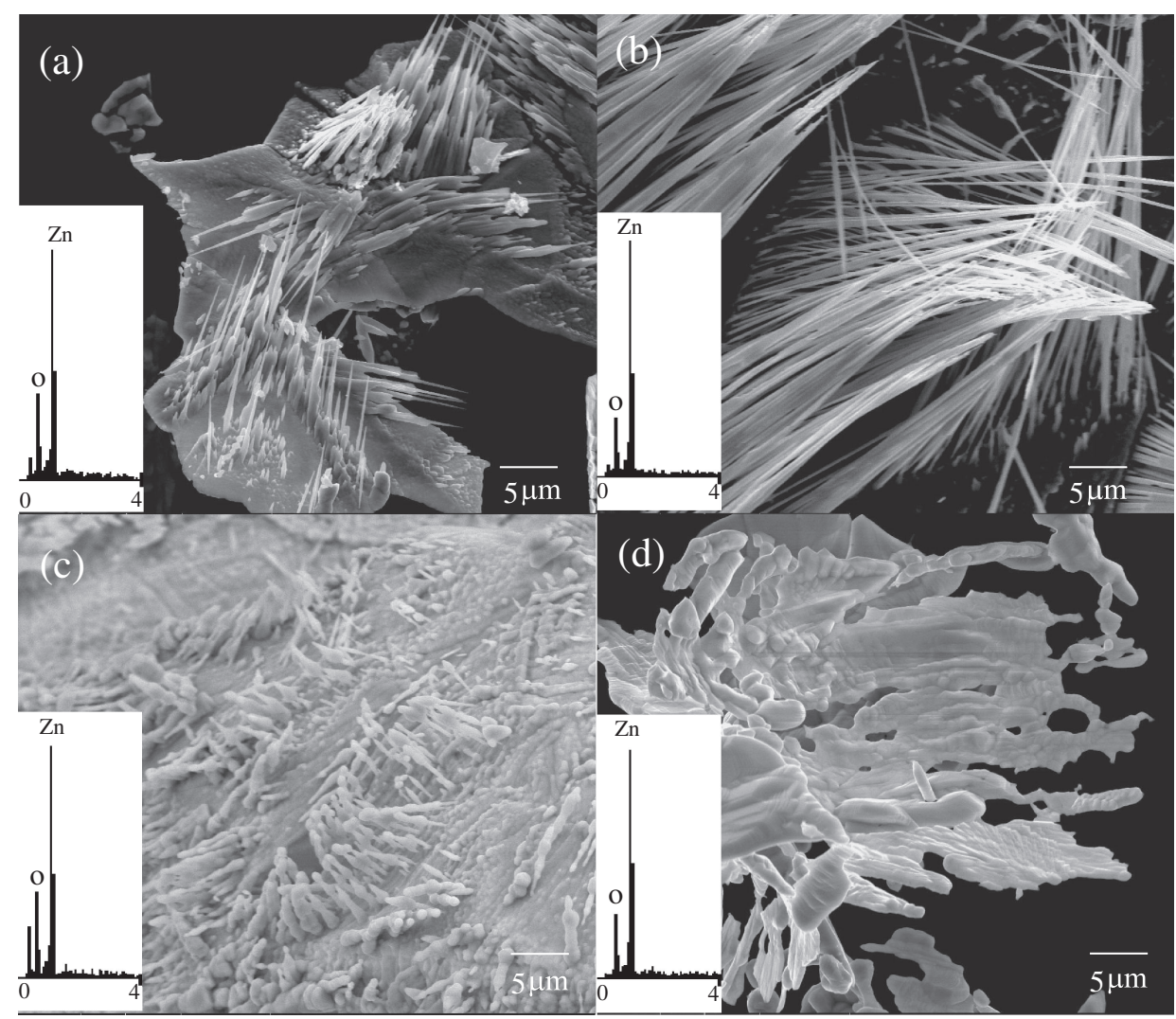

Fig. 1 SEM images of the as-prepared products synthesized at different temperatures of (a) $600^{\circ} \mathrm{C}$, (b) $700^{\circ} \mathrm{C}$, (c) $800^{\circ} \mathrm{C}$ and (d) $900^{\circ} \mathrm{C}$.

The inset corresponds to EDX spectrum of the products.

the low density in the SEM image of the product synthesized at a low temperature of $600^{\circ} \mathrm{C}$. EDX spectra of the asprepared products are shown in Fig. 1 insets. The EDX spectra verify that the products are composed of $\mathrm{Zn}$ and $\mathrm{O}$ without any elements. With increasing the temperature to $700^{\circ} \mathrm{C}$, needle-like structures with high density are observed. In addition, catalyst particle is seen at the tip of the needle-like structures. The EDX analysis reveals that the needle-like structures are also composed of $\mathrm{Zn}$ and $\mathrm{O}$. When the growth temperature increases up to $800^{\circ} \mathrm{C}$, the length and density of the needle-like structures decrease rather than increase. With the further increase of the temperature to $900^{\circ} \mathrm{C}$, the $1 \mathrm{D}$ nanostructures are no longer found in the product. From the EDX spectra taken for all samples, it could be found that the atomic ratio of $\mathrm{Zn}$ to $\mathrm{O}$ is approximately $1: 1$, indicating that the products are $\mathrm{ZnO}$ with high purity.

Figure 2 shows the XRD pattern of the product prepared at a temperature of $700^{\circ} \mathrm{C}$. The XRD pattern shows that all the peaks can be indexed to $\mathrm{ZnO}$ with the hexagonal wurtzite structure. No characteristic peaks of any other phase of $\mathrm{ZnO}$ or any impurity are detected in this sample, indicating the high purity of $\mathrm{ZnO}$.

To understand the growth mechanism of the $\mathrm{ZnO}$ nanostructures, the tip shape of the $\mathrm{ZnO}$ nanostructures was carefully investigated. In spontaneous growth process for the synthesis and formation of one-dimensional nanostructures including nanowires and nanorods, there are two kinds of growth process: vapor-solid (VL) and vapor-liquidsolid (VLS) process. In VL process, the growth species first

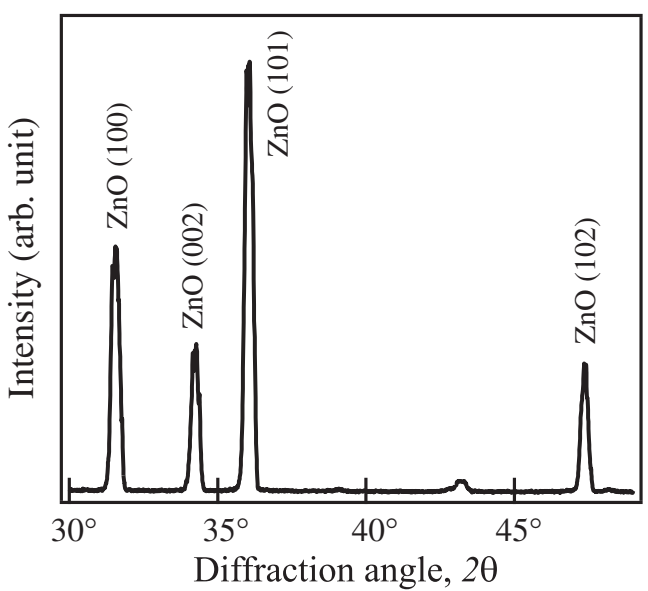

Fig. $2 \mathrm{XRD}$ pattern of the product prepared at a temperature of $700^{\circ} \mathrm{C}$.

are evaporated from the source material and oxidized by the oxygen or air. The typical feature of the VLS process is formation of catalyst droplet. A catalyst forms liquid droplets during the growth and adsorbs the growth species evaporated from the source. The growth species will be supersaturated in the liquid droplet and precipitate at the solid-liquid interface, resulting in the growth of nanowires. Thus the catalyst droplet has been observed at the tip of nanowire grown by the VLS process. Catalyst droplets (or particles) at the tips of the nanostructures are characteristic of the VLS mechanism. ${ }^{7,8)}$ Another type of VLS mechanism is the self-catalytic VLS mechanism. In the self-catalytic VLS growth, any 


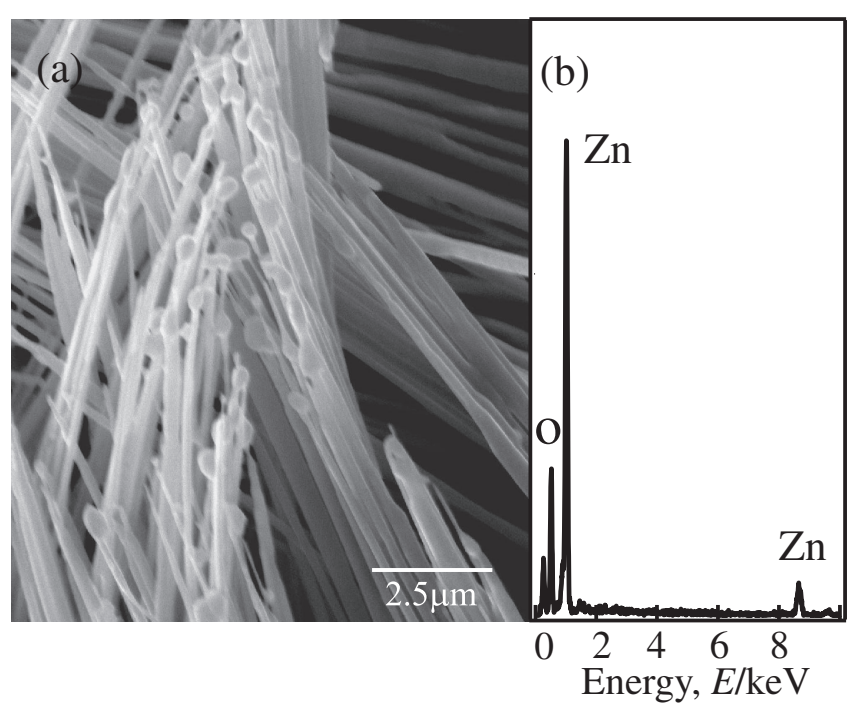

Fig. 3 (a) High-magnification SEM image and (b) EDX spectrum of the $\mathrm{ZnO}$ nanostructures synthesized at $700^{\circ} \mathrm{C}$.

external catalyst is not introduced into the VLS growth. Particularly noteworthy is the fact that in many previous studies of the self-catalytic VLS growth of 1D nanostructures, no catalyst particles have observed at the tips of the 1D nanostructures. ${ }^{9-11)}$ However, in the present experiment, catalyst particles are clearly observable at the tips of a number of nanowires as shown in Fig. 3(a). Thus it is worthwhile to observe catalyst particles at the tips of nanostructures grown via the self-catalytic VLS growth mechanism.

Figure 3(a) demonstrates a high-magnification SEM image of the $\mathrm{ZnO}$ nanostructures synthesized at $700^{\circ} \mathrm{C}$. As it can be seen, nanosized particles are observed on the tips of the $\mathrm{ZnO}$ nanostructures, which gives strong evidence that the $\mathrm{ZnO}$ nanostructures grow via the self-catalytic VLS mechanism. It is suggested that in the present experiment, the $\mathrm{ZnO}$ nanowires were synthesized via the self-catalytic VLS mechanism because any external catalysts were not used and particles were observed at the tips of the wires. On the other hand, the diameter of the nanowires decreases along the growth direction. Another difference of the self-catalytic VLS growth from conventional VLS growth is that the diameter of catalyst droplets changes depending on the growth condition. In the present case, as $\mathrm{Zn}$ species in the catalytic droplets are oxidized to $\mathrm{ZnO}$, the diameters of the catalytic droplets decrease during the growth, resulting in the decrease of the diameter of the nanowires.

EDX measurement was carried out to investigate the components of the droplets. The EDX spectrum is shown in Fig. 3(b). The EDX analysis on the tip reveals that the droplets are composed of $\mathrm{Zn}$ and $\mathrm{O}$. The atomic ratio of $\mathrm{Zn}$ to $\mathrm{O}$ was determined to be $1: 1$ by the EDX analysis, from which the droplets were determined to be $\mathrm{ZnO}$. The EDX result indicates that $\mathrm{ZnO}$ droplets act as a self-catalyst for the growth of the $\mathrm{ZnO}$ nanostructures in the VLS mechanism. The $\mathrm{ZnBr}_{2}$ is decomposed into $\mathrm{Zn}$ or $\mathrm{Zn}$ sub-oxide $\left(\mathrm{ZnO}_{x}\right.$, $x<1$ ) gases in air at temperatures as low as 600 or $700^{\circ} \mathrm{C}$. The $\mathrm{Zn}$ and $\mathrm{Zn}$ sub-oxide have a lower melting point and so they form liquid nano-droplets. The liquid droplets become

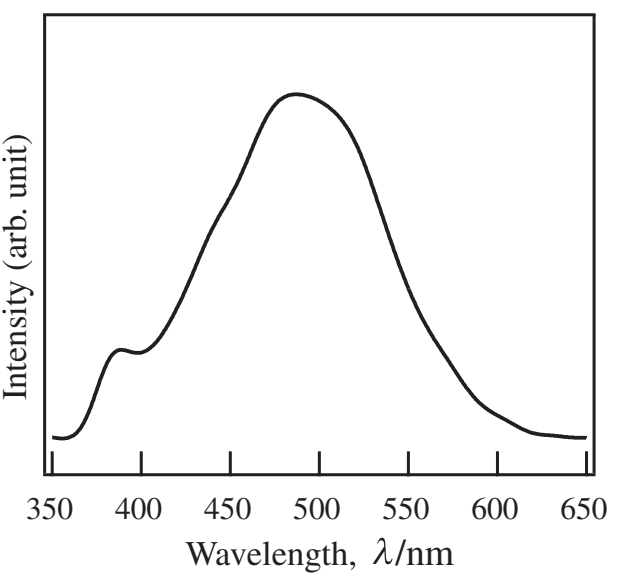

Fig. 4 Room temperature $\mathrm{CL}$ spectrum of the $\mathrm{ZnO}$ nanowires prepared at $700^{\circ} \mathrm{C}$.

supersaturated with $\mathrm{Zn}$ species. Then $\mathrm{Zn}$ particles precipitate in the liquid droplets and react with oxygen in air to form $\mathrm{ZnO}$ nuclei. Subsequently, the growth of $\mathrm{ZnO}$ crystals occurs from the $\mathrm{ZnO}$ nuclei, which leads to the growth of $\mathrm{ZnO}$ nanowires.

Room temperature CL property was measured for the $\mathrm{ZnO}$ nanowires prepared at $700^{\circ} \mathrm{C}$. Figure 4 shows the $\mathrm{CL}$ spectrum of the $\mathrm{ZnO}$ nanowires. A strong and broad green emission peak centered at $500 \mathrm{~nm}$ is observed in the spectrum. It is well known that the broad green emission arises due to the recombination of a photo-generated hole with an electron trapped in singly ionized oxygen vacancy in $\mathrm{ZnO} .{ }^{12)}$ Thus the strong green emission is indicative of high oxygen vacancy density in $\mathrm{ZnO}$. The strong green emission has been observed from $\mathrm{ZnO}$ nanowires because of great fraction of surface and sub-surface oxygen vacancy, which is ascribed to the high surface-to-volume ratio of $\mathrm{ZnO}$ nanowires. ${ }^{13,14)}$ Therefore, the strong green emission should be the characteristic of $\mathrm{ZnO}$ nanowires.

\section{Conclusion}

$\mathrm{ZnO}$ nanowires were successfully synthesized by thermal evaporation process at relatively low temperatures by using zinc salt such as $\mathrm{ZnBr}_{2}$ with relatively low melting and boiling temperatures. Moreover, the process was carried out under air atmosphere without the use of catalysts and substrates. The nanowires began to be formed at a temperature as low as $600^{\circ} \mathrm{C}$ and were synthesized with the high density at $700^{\circ} \mathrm{C}$. The $\mathrm{ZnO}$ nanowires had wurtzite structure. SEM and EDX analysis for the tip of the $\mathrm{ZnO}$ nanowires confirmed the growth proceeded via self-catalytic VLS mechanism. The CL spectrum measured at room temperature for the $\mathrm{ZnO}$ nanowires prepared at $700^{\circ} \mathrm{C}$ showed a strong green emission with peak at $500 \mathrm{~nm}$.

\section{Acknowledgment}

This research was supported by Basic Science Research Program through the National Research Foundation of Korea (NRF) funded by Ministry of Education, Science and Technology (2012-0002613). 


\section{REFERENCES}

1) M. H. Huang, S. Mao, H. Ferick, H. Q. Yan, Y. Y. Yu, H. Kind, E. Weber, R. Russo and P. D. Yang: Science 292 (2001) 1897-1899.

2) B. D. Yao, Y. F. Chan and N. Wang: Appl. Phys. Lett. 81 (2002) $757-$ 759.

3) C. Weigand, J. Tveit, C. Ladam, R. Holmstad, J. Grepstad and H. Weman: J. Cryst. Growth 355 (2012) 52-58.

4) W. T. Chiou, W. Y. Wu and J. M. Ting: Diam. Relat. Mater. 12 (2003) 1841-1844.

5) W. Lee, M. C. Jeong and J. M. Myoung: Acta Mater. 52 (2004) 3949 3957.

6) C. H. Bae, S. M. Park, S. E. Ahn, D. J. Oh, G. T. Kim and J. S. Ha: Appl. Surf. Sci. 253 (2006) 1758-1761.

7) I. Levin, A. Davydov, B. Nikoobakht, N. Sanford and P. Mogilevsky:
Appl. Phys. Lett. 87 (2005) 103110

8) P. Yang, H. Yan, S. Mao, R. Russo, J. Johnson, R. Saykally, N. Morris, J. Pham, R. He and H. J. Choi: Adv. Funct. Mater. 12 (2002) 323331.

9) H. Y. Dang, J. Wang and S. S. Fan: Nanotechnology 14 (2003) 738741.

10) E. A. Stach, P. J. Pauzauskie, T. Kuykendall, J. Goldberger, R. He and P. Yang: Nano Lett. 3 (2003) 867-869.

11) J. H. Zheng, Q. Jiang and J. S. Lian: Appl. Surf. Sci. 257 (2011) 50835087.

12) J. Q. Hu, Y. Bando, J. H. Zhan, Y. B. Li and T. Sekiguchi: Appl. Phys. Lett. 83 (2003) 4414-4416.

13) D. Banerjee, J. Y. Lao, D. Z. Wang, J. Y. Huang, Z. F. Ren, D. Steeves, B. Kimball and M. Sennet: Appl. Phys. Lett. 83 (2003) 2061-2063.

14) R. C. Wang, C. P. Liu, J. L. Huang and S. J. Chen: Appl. Phys. Lett. 86 (2005) 251104-251106. 